\title{
Performance analysis of a novel liquid desiccant-vapor compression hybrid air-conditioning system
}

\author{
Yinglin $\mathrm{Li}^{1 *}$, Xiaosong Zhang ${ }^{2}$, Laizai Tan ${ }^{3}$, Zhongbin Zhang ${ }^{1}$, Wei $\mathrm{Wu}^{1}$, Xueying Xia ${ }^{1}$ \\ (1. Engineering Laboratory for Energy System Process Conversion \& Emission Control Technology of \\ Jiangsu Province, Nanjing Normal University, Nanjing, 210042, China; 2. School of energy and \\ environment, Southeast University, Nanjing, 210096, China; 3. Nanjing Wuzhou Refrigeration Group Co., \\ Ltd, Nanjing, 211100, China)
}

\section{ABSTRACT}

Liquid desiccant-vapor compression hybrid (LDCH) air-conditioning systems are popular for reducing energy consumption. This work tests a conventional $\mathrm{LDCH}$ air-conditioning experimental setup and establishes the corresponding mathematical model to analyze the effect of the concentrated solution branch in the solution-solution heat exchanger (SSHE) on the cooling capacity of the evaporator; the results show that the percentage of cooling capacity loss of the evaporator exceeds $10 \%$ with the small concentration difference of $1.5 \%$ in the conventional LDCH air-conditioning system. Afterwards, a new LDCH air-conditioning system is proposed by adopting an auxiliary regenerator to cut down the cooling capacity loss of the evaporator, and the analysis results show that there is a big temperature drop of the concentrated solution branch after being pretreated by the auxiliary regenerator; under the condition of concentration difference of $2.65 \%$, the inlet temperature of concentrated solution branch from the regeneration side in the SSHE can decrease over $6{ }^{\circ} \mathrm{C}$; and the extra heat load entering the dehumidification side from the regeneration side obviously decreases. Consequently, the evaporator only needs to spend $1.5 \%$ of its cooling capacity on the compensation for the extra heat load.

Keywords: liquid desiccant; auxiliary regenerator; solution branch; concentration difference.

*Corresponding author: Tel.: +86 02585481032 .

E-mail address: ylli@njnu.edu.cn (Y.L. Li)

(C) 2016. This manuscript version is made available under the Elsevier user license http://www.elsevier.com/open-access/userlicense/1.0/ 


\section{Introduction}

Reducing energy consumption of air-conditioning systems is very important for improvement of building energy efficiency. In a conventional air-conditioning system, air is conditioned by passing it over a cooling coil to achieve both cooling and dehumidification; dehumidification is realized by cooling the air to below its dew point. As a result, the dehumidified air is cooler than the required indoor comfort level, which in turn causes reheating and further energy loss. Meanwhile, since chilled water with a relatively lower temperature is needed, the performance of chillers is decreased. Furthermore, health problems can occur because the condensed water makes the coil surface a breeding ground for bacteria. A Liquid desiccant air-conditioning system has been gaining attentions as an alternative to the conventional dehumidification system. The liquid desiccant system can dehumidify the humid air by the direct contact between the humid air and concentrated solution. The diluted solution after the dehumidification has to be concentrated to use it again. Therefore, the system mainly consists of a dehumidifier and a regenerator. Moreover, the liquid desiccant air-conditioning system can be driven by low-temperature heat source. From this feature, the efficiency of the system is expected to be enhanced by use of the waste heat from a compression heat pump for the regeneration of the diluted solution. In this study, we focus on the liquid desiccant-vapor compression hybrid (LDCH) air-conditioning system consisting of a liquid desiccant system and a vapor compression heat pump [1-3].

Some previous studies on the LDCH air-conditioning system are described as follows. 1) Prior works on developing new systems of LDCH air-conditioning units: Yadav (1995) investigated the effect of operating parameters on the performance of the hybrid solar air conditioning system. The system consists of liquid desiccant cycles and conventional vapor compression. Lithium bromide is used as solution in the liquid desiccant cycle and R-11 is used as refrigerant in the vapor compression system. The results show that the system is more promising under high latent heat load [4]. Ani et al. (2005) established a hybrid 
system consisting of vapor compression system, liquid desiccant system and solar collector, and investigated the optimization of the absorber packing height by experiments [5]. Gasparella et al. (2005) simulated a hybrid system of ground-source heat pump and liquid desiccant. This novel system can save around $30 \%$ of the primary energy annually compared with the conventional systems [6]. Zhang et al. (2010 and 2012) proposed a new frost-free hybrid air-conditioning system, which integrated with liquid desiccant dehumidification units. In the system, a heat pump is used for the solution regeneration and pre-cooling in summer. In winter, frosting can be avoided by dehumidifying the air before it enters into the evaporator of the heat pump. The results show that the coefficient of performance (COP) is $30-40 \%$ higher than that of the heat pump integrated with an electric heater [7-8]. Mohan et al. (2015) investigated a new liquid desiccant-vapor compression hybrid air conditioner. In this hybrid system, the desiccant dehumidifier is placed after the evaporator, and the regenerator is after the condenser of the AC unit [9].

2) Prior works on seeking methods to improve the designs of configuration: Wu et al. (2006) investigated an internally cooled liquid desiccant dehumidifier. The evaporator of the vapor compression system is set in the dehumidifier to remove the condensing heats of vapor and cool process air, and the condenser equipped in the regenerator is used to heat the regenerating solution [10]. Mohan et al. (2008) investigated the characteristics of absorber and regenerator columns for hybrid liquid desiccant air-conditioning system. The simulation model of countercurrent absorber and regenerator is developed on the basis of heat and mass balance and heat and mass analogy [11].

3) Prior works about examination, test and simulation of system performance: Bergero and Chiari (2010 and 2011) examined the performance of an air dehumidification system integrated with a vapor compression inverse cycle. Air is dehumidified in an air-solution membrane contractor and cooled by a vapor compression cycle; lithium chloride solution is cooled by a vapor compression unit and regenerated in another membrane. The results show $60 \%$ energy savings at high latent heat load compared with a 
traditional direct expansion air conditioning system [12-13]. Yamaguchi et al. (2011) conducted the performance evaluation test of a hybrid liquid desiccant air-conditioning system consisting of a conventional liquid desiccant system and a vapor compression heat pump. The main feature of this system is that the absorber and regenerator are integrated with the evaporator and condenser, respectively. The results showed that the COP of the system was 2.71 [14]. Zhao et al. (2011) investigated the real operating performance of the temperature and humidity independent control air-conditioning system. The system is composed of a two stage total heat recovery device and a two-stage air handling device coupled with refrigeration cycles. The total heat recovery device is used to recover the energy from return air to decrease the energy consumption in the fresh air handling process. In the heat pump driven air handling device, the diluted solution from the dehumidification module is heated by the exhaust heat from the condenser, and the hot concentrated solution from the generation module is cooled by the evaporator. [15]. Lazzarin and Castellotti (2007) conducted energy savings of a novel desiccant air-handling unit with that of a traditional mechanical dehumidifier. In the air-handling unit, the diluted desiccant solution is regenerated using the thermal energy supply from a primary heat pump condenser, while air regeneration is used a secondary heat pump condenser [16]. Li et al. (2005) carried out numerical simulation to predict the performance a new type of fresh air processor system in different meteorological conditions. The system is combined of liquid desiccant total heat recovery device and a refrigeration cycle, and divided into two parts, the first part is appeared in the middle solution for the purpose of total heat recovery and the second part appeared in the left and right side where liquid desiccant exchanges sensible heat with the refrigeration cycle [17].

4) Prior works on removing the superfluous heat capacity of the condenser: the amount of heat from the condenser in a LDCH air-conditioning system is often more than the heat needed in desiccant regeneration process. To remove the superfluous condensing heat, Zhang et al. (2012) used two different methods for removing the extra heat. In the first method, they used a water-cooled assistant condenser; in 
the second method, they added an air-cooled assistant condenser. The coefficient performance of the system with the water-cooled condenser was approximately 35\% higher than the basic system [18]. Niu et al. (2012) studied the capacity matching of a new hybrid liquid desiccant air conditioning system, which consisted of a liquid desiccant dehumidification and a heat pump system with double condensers. The results show that the system with a double-condenser is a feasible configuration for achieving capacity matching [19]. Chen et al. (2014) proposed a novel temperature and humidity independent control air-conditioning system based on liquid desiccant. In the system, an air-cooled condenser works in series with a solution-cooled condenser, and the refrigerant from compressor rejects its condensation heat firstly to the solution-cooled condenser and then to the air-cooled condenser. This makes capacity matching between the dehumidification and regeneration processes more efficient [20].

However, these reviewed studies above had paid few attentions to the heat exchanging process between the concentrated solution from regeneration side and the diluted solution from the dehumidification side. In a LDCH air-conditioning system, the solution-solution heat exchanger (SSHE) lies between the concentrated solution branch from regeneration side and the diluted solution branch from dehumidification side, and the concentrated solution branch from the regeneration side is pre-cooled in the SSHE before entering the dehumidification side, but the temperature of concentrated solution branch leaving from the SSHE is still higher than the temperature of solution in dehumidification side. Therefore, the concentrated solution branch delivered from the SSHE will increase the additional consumption of cooling capacity of the evaporator, and this process becomes energy inefficient. Consequently, the effect of concentrated solution branch on the heating exchanging process of the SSHE deserves a further investigation.

Obviously, the temperature and the flow rate of concentrated solution branch are the key factors which heavily influence the additional consumption of cooling capacity of the evaporator. One of the novelties of this work is that the effect of concentrated solution branch fluid on the heat exchanging process of the 
SSHE is analyzed based on a conventional LDCH air-conditioning experiment setup. A further contribution is that a new LDCH air-conditioning system is proposed to reduce the additional consumption of evaporating load of heat pump. The results can help to design energy-efficient LDCH air-conditioning systems.

\section{Description of a conventional LDCH air-conditioning system}

\subsection{Working principle}

The schematic of a conventional LDCH air-conditioning system is shown in Fig.1, which consists of regeneration module, dehumidification module, SSHE, and a vapor compression heat pump. The desiccant solution is concentrated in the regenerator after being heated by the condenser of heat pump; the desiccant solution imbibes water from the processed air in the dehumidifier after being cooled in the evaporator. In other words, the condenser of heat pump is used to supply heat load for inspissating desiccant solution, and the evaporator serves to provide cooling capacity for dehumidifying process.

It should be noticed that the liquid desiccant circulates in the LDCH system. As shown in Fig.1, in the dehumidification side, the desiccant solution (point 4) from the diluted solution pump flows successively through the evaporator (point 8), the rotameter, dehumidifier, diluted solution tank and the rotameter (point 2), afterwards mixes with the concentrated solution branch (point 7) which comes from the SSHE, finally backs to the diluted solution pump (point 4); the solution branch (point 2) from the diluted solution tank passes through the SSHE (point 6). Similarly in the regeneration side, the desiccant solution (point 3) from the concentrated solution pump flows ordinally through the condenser (point 9), the rotameter, regenerator, concentrated solution tank (point 1) and the rotameter, afterwards combines with the diluted solution branch (point 6) from the SSHE, finally returns to the concentrated solution pump (point 3); the solution branch (point 5) from the concentrated solution tank passes through the SSHE (point 2).

Fig.2 presents the $T-x$ diagram of desiccant solution, the process 4-8-2 stands for the solution process of 
being cooled in the evaporator and diluted in the dehumidifier, the process 3-9-1 is the solution process of being heated in the condenser and dehydrated in the regenerator; and the process 2-6 and process 5-7 indicate the heat transfer between diluted solution and concentrated solution in the SSHE. This work defines the temperature difference between point 7 and point 2 as temperature difference of $\Delta t$; as shown in Fig.2, we can see that the temperature of solution point 7 is higher than those of point 2 , so the enthalpy of solution point 7 is commonly larger than that of solution point 2; that is to say, accompanied by the concentrated solution branch (point 7), some additional heat load is carried into the dehumidification side from regeneration side. Since the temperature of spraying solution above the dehumidifier needs to remain invariable and maintain at a lower level, so the evaporator has to spend a considerable share of its cooling capacity on countervailing the extra heat load, so the cooling capacity of evaporator using for dehumidification process decays and gets an unsatisfactory loss.

\subsection{Mathematical model}

The dehydration rate from liquid desiccant to outdoor air in the regenerator is commonly more than the moisture absorption rate from the processed air to liquid desiccant in the dehumidifier, to prevent the balance disorder of solution concentration in the LDCH air-conditioning system, a certain amount of water will be supplemented into regeneration side. By solving the mass and energy balances of different components simultaneously, key equations of the LDCH air-conditioning system are presented in detail in Appendix A.

It should also be noted that the concentrations in the concentrated solution tank and diluted solution tank are defined as $x_{1}$ and $x_{2}$ respectively; the average value of $x_{1}$ and $x_{2}$ is a fixed value of $26 \%$, and the solution temperature of diluted solution tank is assumed to remain $25^{\circ} \mathrm{C}$.

\subsection{Experimental setup}

The experimental facility is shown in Fig.3, the rated input power of the scroll compressor is $8.0 \mathrm{~kW}$, 
the refrigerant of the vapor compression system is $\mathrm{R} 407 \mathrm{C}$ and the liquid desiccant is aqueous solution of lithium chloride. The main body of the dehumidifier and regenerator is the structure of a packed-bed tower. The packed-bed consists of specially impregnated and corrugated cellulose paper sheets with $30^{\circ}$ flute angles. The packed-bed tower is cubical with $90 \mathrm{~cm}$ in width, $78 \mathrm{~cm}$ in height and $30 \mathrm{~cm}$ in thickness; and its specific surface area is $450 \mathrm{~m}^{2} / \mathrm{m}^{3}$. There are two solution storage tanks and two pumps in this system. One tank is used for storing diluted liquid desiccant solution while the other is for the concentrated solution. The concentration of liquid desiccant is regulated by adding water or lithium chloride particles to the solution. During the experiment process, the core devices of the LDCH air-conditioning system, such as the dehumidifier, the regenerator and solution tanks, are thermally insulated.

The temperatures of the air and the desiccant solution are measured by K-type thermocouples; also the humidity and temperature sensors are used to measure the parameters of the inlet and outlet air. The density of desiccant solution is measured by the specific gravity hydrometer and the air flow rate by the spraying nozzle. The mass concentration of the aqueous lithium chloride is indirectly tested by measuring the density and temperature of the solution, and the properties of the aqueous lithium chloride can be found in Ref. [21]. According to the density and temperature of the desiccant solution, its weight concentration can be calculated. All the experiments are finished in the environmental laboratory, and the main measurement instruments are shown in Table 1.

\section{Experimental results and analysis}

Fig.4 shows the variation of the branch fluid percentage of liquid desiccant with the solution concentration difference. It can be claimed that the branch fluid percentage declines sharply with the accretion of solution concentration difference; also the trend of experiment results is in good agreement with that of the model.

Fig.5 illustrates the variation of cooling capacity loss of the evaporator with the concentration 
difference of desiccant solution. It can be observed that with the decrease of concentration difference, the cooling capacity loss of the evaporator increases quickly. Particularly, as depicted in Fig. 6, when the concentration difference of desiccant solution drops to $0.5 \%$, the percentage of cooling capacity loss reaches unbelievably as high as $37 \%$. The dramatic rise of cooling capacity loss is due to the increment of the solution branch flow rate while decreasing the concentration difference; and the higher the branch flow rate of concentrated solution, the more the extra heat load being carrying to dehumidification side. Also, from the Fig.5 and Fig.6, we can conclude that a bigger concentration difference of solution should be recommended in the conventional LDCH air-conditioning system.

As shown in Fig.5 and Fig.6, it also can be pointed out that the main trend of experiment results is consistent with the modeling value, the deviation value between experiment value and modeling value is due to the real effect of the heat insulation in the experimental setup, and the energy leakage is unavoidable during the experimental tests. Compared with the smaller concentration difference, the influence of energy leakage on the bigger concentration difference is more obvious. This can be explained that the bigger concentration difference of desiccant solution, the lower the absolute value of cooling capacity loss; but the absolute value of energy leakage of cooling capacity hardly fluctuates at different concentration differences. Consequently, energy leakage shows a heavier influence on the cooling capacity loss at a bigger concentration difference of desiccant solution, and the deviation value between experiment value and modeling value increases with the accretion of concentration difference.

As presented in Fig.7, we can conclude that percentage of cooling capacity loss with bigger temperature difference $\Delta t$ is significantly higher than that with smaller temperature difference. Even the temperature difference is as low as $8{ }^{\circ} \mathrm{C}$, the percentage of cooling capacity loss still stands up to $10 \%$ with concentration difference of $1.5 \%$, and this significantly restricts the improvement of system performance of conventional LDCH air-conditioning system. Detail experimental results are provided in Table.2, the 
average of cooling capacity loss percentage of the evaporator exceeds $10 \%$. Measures should be taken to change this unfavorable situation, and this work proposes a new $\mathrm{LDCH}$ air-conditioning system by adopting an auxiliary regenerator in the following section.

\section{Description of a new LDCH air-conditioning system}

A new conceiving LDCH air-conditioning system is shown in Fig.8; an auxiliary regenerator in the regeneration side is introduced to reduce the cooling capacity loss of the evaporator. The desiccant solution point 3 leaving from the concentrated solution pump is separated into the condenser and the auxiliary regenerator; the solution branch (point 3) sent into the auxiliary regenerator is dehydrated and cooled down to state point 5, then flows through the regulative valve, and is delivered into the SSHE to be further cooled down to a lower temperature (point 7). Compared with a conventional LDCH air-conditioning system, this method can reduce the temperature difference between the solution point 7 from the regeneration side and the solution (point 2) from the dehumidification side; and the lower temperature difference can abate the cooling capacity loss of the evaporator.

Fig.9 presents the $T-x$ diagram of desiccant solution in this new LDCH air-conditioning system. The process 4-8-2 stands for the solution process of being cooled in the evaporator and diluted in the dehumidifier, and the process 3-9-1 is the solution process of being heated in the condenser and inspissated in the regenerator. The process 2-6 indicates that the diluted solution is pre-heated in the SSHE, the process 3-5 means that the concentrated solution branch is pre-cooled and dehydrated in the auxiliary regenerator, and process 5-7 indicates that the concentrated solution branch is further cooled in the SSHE. Comparing Fig. 2 and Fig.9, we can find out that the temperature difference between solution point 2 and point 7 declines obviously, this is own to the temperature difference of $\Delta t_{3,5}$ caused by the auxiliary regenerator.

Also, by solving the mass and energy balances of different components simultaneously, key equations of the new LDCH air-conditioning system are presented in detail in Appendix B, and the modeling of new 
LDCH air-conditioning system is based on the assumption that the operation condition and parameters of regeneration side, such as the outdoor air flow rate, the circulating flow rate of solution pump and the temperature of solution tank, are exactly the same with that for the conventional LDCH air-conditioning system.

It may also be noted that, while $m_{\mathrm{e} 1}$ is equal to zero in the equation (15), the new LDCH air-conditioning system can be simplified, and the solution concentration of point 5 equals to that of point 3 . But for the conventional LDCH air-conditioning system, the liquid desiccant concentration of point 5 is equal to that of point 1(Fig.1), this simplified LDCH system is not the same with the conventional LDCH system.

\section{Discussions}

\subsection{Variation of temperature difference}

Comparison of the experiment value of conventional LDCH air-conditional system and modeling value of the new LDCH air-conditioning system is presented in Table.3. As shown in Table.3, there is a big temperature drop of concentrated solution branch after being pretreated by the auxiliary regenerator. Under the condition of concentration difference of $2.65 \%$, the temperature drop $\Delta t_{3,5}$ is about $7.0{ }^{\circ} \mathrm{C}$ while both $\beta_{\mathrm{e}}$ and $\beta_{\mathrm{d}}$ are 1.0 , and $\Delta t_{3,5}$ is still as high as $6.3{ }^{\circ} \mathrm{C}$ even with a deduction of viewing both $\beta_{\mathrm{e}}$ and $\beta_{\mathrm{d}}$ as 0.9 ; in other words, the inlet temperature of concentrated solution branch from the regeneration side in the SSHE can decrease over $6{ }^{\circ} \mathrm{C}$. Expected in an ideal circumstance, the temperature difference between solution point 7 and point 2 will be less than $1.8{ }^{\circ} \mathrm{C}$. Compared Table. 2 and Table.3, under the condition of concentration difference of $2.65 \%$, the temperature difference between solution point 7 and point 2 declines from $7.8^{\circ} \mathrm{C}$ to $1.5^{\circ} \mathrm{C}$; from Fig.7, we can conclude that the loss percentage $\theta_{\mathrm{c}}$ of cooling capacity will decrease from $8.2 \%$ to about $1.5 \%$.

From Table.3, we can see that with the decrease of the concentration difference $\Delta x$, the temperature 
difference of $\Delta t_{3,5}$ slightly reduces; even the solution concentration difference of $\Delta x$ falls to $1.26 \%$, the temperature difference of $\Delta t_{3,5}$ can still be as high as $6.0{ }^{\circ} \mathrm{C}$ with a fixed value of 0.9 to both $\beta_{\mathrm{e}}$ and $\beta_{\mathrm{d}}$. Consequently, there is a significantly decline in temperature difference between point 7 and point 2 , and the extra heat load entering the dehumidification side from the regeneration side obviously decreases, and the cooling capacity of evaporator gets a less loss to compensate the extra heat load.

Fig.10 depicts the variation of solution temperature difference with solution concentration difference. From fig.10, we can see that the solution temperature difference of the new LDCH system significantly decreases to about $2{ }^{\circ} \mathrm{C}$ compared with the conventional LDCH air-conditioning system; and that the solution temperature difference of the new LDCH system slightly reduces with the increase of the solution concentration difference, this indicates that a bigger concentration difference of liquid desiccant is more beneficial to lighten the cooling capacity loss of the evaporator.

\subsection{Variation of solution concentrations}

Figs. (11-13) depict the variation of solution concentration. From Fig.10 and Fig.11, It can be seen that, comparing with the conventional LDCH air-conditioning system, the concentrations of both solution point 1 and point 5 obviously decline in the new LDCH air-conditioning system. On the contrary, As shown in Fig.13, we can find out that solution concentrations of both point 1 and point 5 in the new LDCH air-conditioning system are slightly higher than those in the conventional LDCH air-conditioning system.

Figs. (11-13) indicate that the concentrated solution branch (point 5) can obtain higher solution concentration under the condition of bigger solution concentration difference, and this can benefit the dehumidifying process for the humid air, because a higher solution concentration has a lower surface water vapor pressure, and the lower vapor pressure promotes the mass transfer process and gives better dehumidification effect. All this suggests that the liquid desiccant with bigger concentration difference of $2.65 \%$ of is more suitable for the new LDCH air-conditioning system. 


\section{Conclusions}

The present work tests a conventional LDCH air-conditioning system and establishes the corresponding mathematical model to analyze the effect of the concentrated solution branch in the SSHE on the cooling capacity of the evaporator; also a new LDCH air-conditioning system is proposed by adopting an auxiliary regenerator to cut down the cooling capacity loss of the evaporator. The conclusions are as follows:

(1) As far as the conventional $\mathrm{LDCH}$ air-conditioning system is concerned, even the temperature difference between the outlet of concentrated solution branch and the inlet of diluted solution branch in the SSHE is as low as $8{ }^{\circ} \mathrm{C}$, the percentage of cooling capacity loss of the evaporator still exceeds $10 \%$ with the concentration difference of $1.5 \%$; and this significantly restricts the enhancement of system performance of the conventional LDCH air-conditioning system.

(2) For the new LDCH air-conditioning system, there is a big drop of temperature of concentrated solution branch after being pretreated by the auxiliary regenerator. Under the condition of concentration difference of $2.65 \%$, the inlet temperature of concentrated solution branch from the regeneration side in the SSHE can decrease over $6{ }^{\circ} \mathrm{C}$, the extra heat load entering the dehumidification side from the regeneration side obviously decreases, and the loss percentage $\theta_{\mathrm{c}}$ of cooling capacity lowers from $8.2 \%$ to about $1.5 \%$.

(3) A bigger concentration difference of liquid desiccant can be more beneficial to lighten the cooling capacity loss of the evaporator; also can help the concentrated solution branch in the SSHE obtain higher solution concentration, this can gives better dehumidification effect for the humid air. The liquid desiccant with bigger concentration difference of $2.65 \%$ is optimal for the new LDCH air-conditioning system.

In a word, adding an auxiliary regenerator is a valid method to cut down the pernicious influence of the concentrated solution branch on the cooling capacity of the evaporator. The results and conclusions can be useful to design an energy-efficient LDCH air-conditioning system. 


\section{Acknowledgments}

The authors gratefully acknowledge supports through National Science Foundation of Jiangsu Province (BK20140924) and the China Postdoctoral Science Foundation (2012M520970); the authors also gratefully acknowledge the experiment support of Nanjing Wuzhou Refrigeration Group Co., Ltd.

\section{Appendix A. Details of key equations of heat and mass transfer}

To analyze the effect of temperature difference of the SSHE on the cooling capacity of evaporator, the mass and energy balances of hybrid system should be established. The main equations for heat and mass transfer process are listed as follows:

1) Mass balance of dehumidification side

During the steady operation of the conventional LDCH air-conditioning system, by assuming that the circulating solution flow rate of the diluted solution equals to that of the concentrated solution pump, the concentration of solution in dehumidification side remains constant, therefore,

$$
\begin{aligned}
& \left(m_{c} \alpha-m_{d}\right) x_{7}=m_{c} \alpha x_{2} \\
& \left(m_{c} \alpha-m_{d}\right) x_{7}+\left(m_{c}-m_{c} \alpha+m_{d}\right) x_{2}=m_{c} x_{4}
\end{aligned}
$$

Where $m_{\mathrm{c}}$ stands for the circulating solution flow rate of the diluted and concentrated solution pump, and $\alpha$ means the percentage of solution branch fluid in the dehumidification side to the circulating solution flow rate $m_{\mathrm{c}} ; x_{2}, x_{4}$ and $x_{7}$ refer to the solution concentrations of point 2,4 and 7 , respectively. And $m_{\mathrm{d}}$ is the water absorption rate of the solution from the processed air in the dehumidifier.

2) Mass balance of regeneration side

$$
\begin{aligned}
& m_{c} \alpha x_{6}+m_{c}(1-\alpha) x_{1}=m_{c} x_{3} \\
& x_{1}=x_{5}=x_{7} \\
& x_{2}=x_{6}
\end{aligned}
$$


Where $m_{\mathrm{e} 1}$ means the released moisture rate from the liquid desiccant to outdoor air in the auxiliary regenerator, and $m_{\mathrm{e}}$ represents the total released moisture rate from the liquid desiccant to outdoor air in the regeneration side. $x_{1}, x_{3}, x_{5}$ and $x_{6}$ are the different solution of point $1,3,5$ and 6 , respectively.

Combining equations (1) and (4), we have

$x_{1}=\frac{m_{c} \alpha}{\left(m_{c} \alpha-m_{d}\right)} x_{2}$

Substituting equation (6) in equation (3) yields

$x_{3}=\frac{\left(m_{c}-m_{d}\right) \alpha}{m_{c} \alpha-m_{d}} x_{2}$

Using equations (2), (4) and (6), we can obtain

$x_{4}=\left(1+\frac{m_{d}}{m_{c}}\right) x_{2}$

Defining the concentration difference of solution $\Delta x$ as

$\Delta x=x_{1}-x_{2}$

While $\Delta x$ and $x_{2}$ as known parameters, according to the above equations (8-12), all the concentrations of other liquid desiccant points can be calculated.

3) Supplemental filling water rate in regeneration side

The supplemental filling water can be defined as,

$m_{s}=m_{e}-m_{d}$

Where $m_{\mathrm{e}}$ represents the total dehydration rate from the desiccant solution to the outdoor air in the regeneration side, and $m_{\mathrm{s}}$ is the supplemented filling water in the regeneration side.

4) Cooling capacity loss of the LDCH air-conditioning system

The loss of cooling capacity can be calculated as follows:

$q_{c o}=\left(m_{c} \alpha-m_{d}\right) h_{7}-m_{c} \alpha h_{2}$

$q_{\text {eva }}=m_{c}\left(h_{4}-h_{8}\right)$ 
$\theta_{c}=q_{c o} / q_{\text {eva }}$

Where $q_{\mathrm{co}}$ means the loss of cooling capacity of the evaporator and $q_{\mathrm{eva}}$ denotes the cooling capacity of the evaporator. $\theta_{\mathrm{c}}$ is the loss percentage of cooling capacity of the evaporator.

\section{Appendix B. Key equations of new LDCH air-conditioning system}

1) Mass and energy transfer of the auxiliary regenerator

$q_{e 1}=\beta_{e}\left(\alpha q_{e}\right)$

$m_{e 1}=\beta_{d}\left(\alpha m_{e}\right)$

Where $q_{\mathrm{e} 1}$ stands for the removal heat load from liquid desiccant to outdoor air in the auxiliary regenerator, $m_{\mathrm{e} 1}$ represents the dehydration rate from the desiccant solution to the outdoor air in the auxiliary regeneration, and $q_{\mathrm{e}}$ stands for the total removal heat load in the regeneration side, $m_{\mathrm{e}}$ represents the total dehydration rate in the regeneration side; $\beta_{\mathrm{e}}$ and $\beta_{\mathrm{d}}$ are the effective coefficients of heat transfer and mass transfer, respectively; in an ideal heat and mass transfer process, both $\beta_{\mathrm{e}}$ and $\beta_{\mathrm{d}}$ equal to 1.0 , in a real heat and mass transfer process, this work defines both $\beta_{\mathrm{e}}$ and $\beta_{\mathrm{d}}$ as 0.9 .

2) Mass balance of dehumidification side

While remaining the solution concentration of dehumidification side invariable, the key equations are the same as those of conventional LDCH hybrid system.

3) Mass balance of regeneration side

$\left(m_{c} \alpha-m_{d}\right) x_{5}=\left(m_{c} \alpha-m_{d}+m_{e 1}\right) x_{3}$

$x_{5}=x_{7}$

Combining equations (1) and (17), we have

$x_{5}=\frac{m_{c} \alpha}{\left(m_{c} \alpha-m_{d}\right)} x_{2}$

Substituting equation (18) in equation (16) gives 
$x_{3}=\frac{m_{c} \alpha}{m_{c} \alpha-m_{d}+m_{e 1}} x_{2}$

Using equations (2) and (18), we can obtain

$x_{4}=\left(1+\frac{m_{d}}{m_{c}}\right) x_{2}$

Inserting the equations (5) and (19) into equation (3) yields

$x_{1}=\frac{\alpha}{1-\alpha}\left[\frac{m_{c}}{m_{c} \alpha-m_{d}+m_{e 1}}-1\right] x_{2}$

\section{References}

[1] T. Abdulrahman, B.M. Sohif, M.Y. Sulaiman, et al., Survey of hybrid liquid desiccant air conditioning systems, Renewable and Sustainable Energy Reviews 20 (2013) 186-200.

[2] A.T. Mohammad, S.B. Mata, M.Y. Sulaimana,et al., Survey of liquid desiccant dehumidification system based on integrated vapor compression technology for building applications, Energy and Buildings 62 (2013) 1-14.

[3] Y.G. Yin, J.F. Qian, X.S. Zhang, Recent advancements in liquid desiccant dehumidification technology, Renewable and Sustainable Energy Reviews 31 (2004) 38-52.

[4] Y.K. Yadav, Vapour-compression and liquid-desiccant hybrid solar space conditioning system for energy conservation, Renewable Energy 6 (1995) 719-723.

[5] F.N. Ani, E.M. Badawi, K.S. Kannan, The effect of absorber packing height on the performance of a hybrid liquid desiccant system, Renewable Energy 30 (2005) 2247-2256.

[6] A. Gasparella, G.A. Longo, R. Marra, Combination of ground source heat pumps with chemical dehumidification of air, Applied Thermal Engineering 25(2005) 295-308.

[7] L. Zhang, C.B. Dang, H. Eiji, Performance analysis of a no-frost hybrid air conditioning system with integrated liquid desiccant dehumidification, International Journal of Refrigeration 33 (2010) 116-124.

[8] L. Zhang, H. Eiji, S. Michiyuki, Combination of air-source heat pumps with liquid desiccant dehumidification of air, 
Energy Conversion and Management 57(2012) 107-116.

[9] B.S. Mohan, S. Tiwari, M.P. Maiya, Experimental investigations on performance of liquid desiccant-vapor compression hybrid air conditioner, Applied Thermal Engineering 77 (2015) 153-162.

[10] A.M. Wu, C.L. Li, H.F. Zhang, The primary research on liquid desiccant dehumidifier with cooling capacity using compressible heat pump system, International Refrigeration and Air Conditioning Conference at Purdue, 2006, p. 17-20.

[11] B.S. Mohan, M.M. Prakash, S. Tiwari, Performance characterization of liquid desiccant columns for a hybrid air-conditioner, Applied Thermal Engineering 28(2008) 1342-1355.

[12] S. Bergero, A. Chiari, Performance analysis of a liquid desiccant and membrane contactor hybrid air-conditioning system, Energy and Buildings 42 (2010) 1976-1986.

[13] S. Bergero, A. Chiari, On the performances of a hybrid air-conditioning system in different climatic conditions, Energy 36 (2011) 5261-5273.

[14] S. Yamaguchi, J. Jeong, K. Saito, et al., Hybrid liquid desiccant air-conditioning system: experiments and simulations, Applied Thermal Engineering 31 (2011) 3741-3747.

[15] K. Zhao, X.H. Liu, T. Zhang, et al., Performance of temperature and humidity independent control air-conditioning system in an office building, Energy and Buildings 43 (2011) 1895-1903.

[16] R.M. Lazzarin, F. Castellotti, A new heat pump desiccant dehumidifier for supermarket application, Energy and Buildings 39 (2007) 59-65.

[17] Z. Li, X.H. Liu, Y. Jiang, et al., New type of fresh air processor with liquid desiccant total heat recovery, Energy and Buildings 37 (2005) 587-593.

[18] T. Zhang, X.H. Liu, Y. Jiang, Performance optimization of heat pump driven liquid desiccant dehumidification systems, Energy and Buildings 52 (2012) 132-144.

[19] X.F. Niu, F. Xiao, Z.J. Ma, Investigation on capacity matching in liquid desiccant and heat pump hybrid 
air-conditioning systems, International Journal of Refrigeration 35 (2012) 160-170.

[20] Y. Chen, Y.G. Yin, X.S. Zhang, Performance analysis of a hybrid air-conditioning system dehumidified by liquid desiccant with low temperature and low concentration, Energy and Buildings 77 (2014) 91-102.

[21] M.R. Conde, Properties of aqueous solutions of lithium and calcium chlorides: formulations for use in air conditioning equipment design, International Journal of Thermal Sciences 43 (2004) 367-382. 


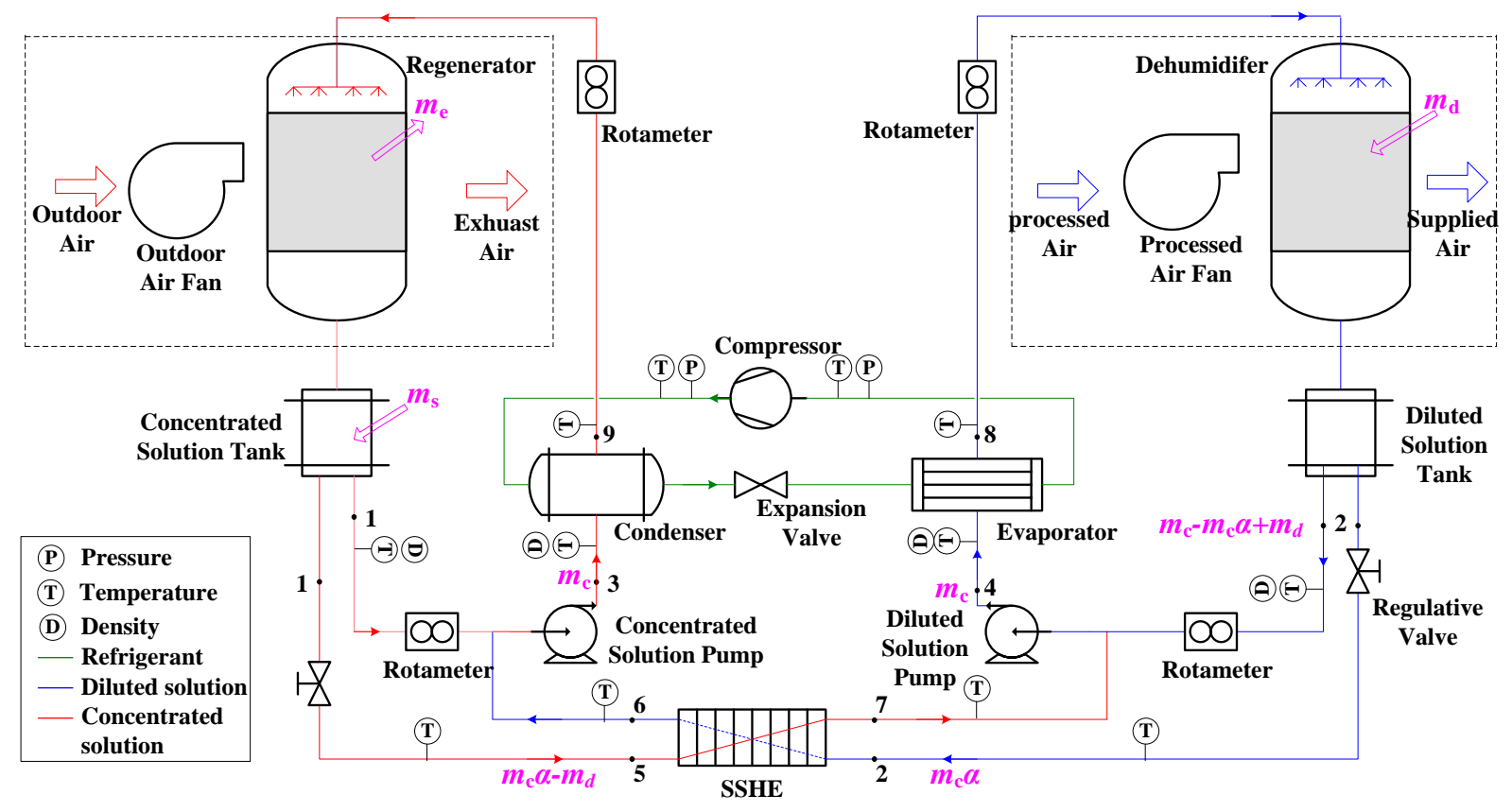

Fig.1. Schematic of a conventional LDHP air-conditioning system

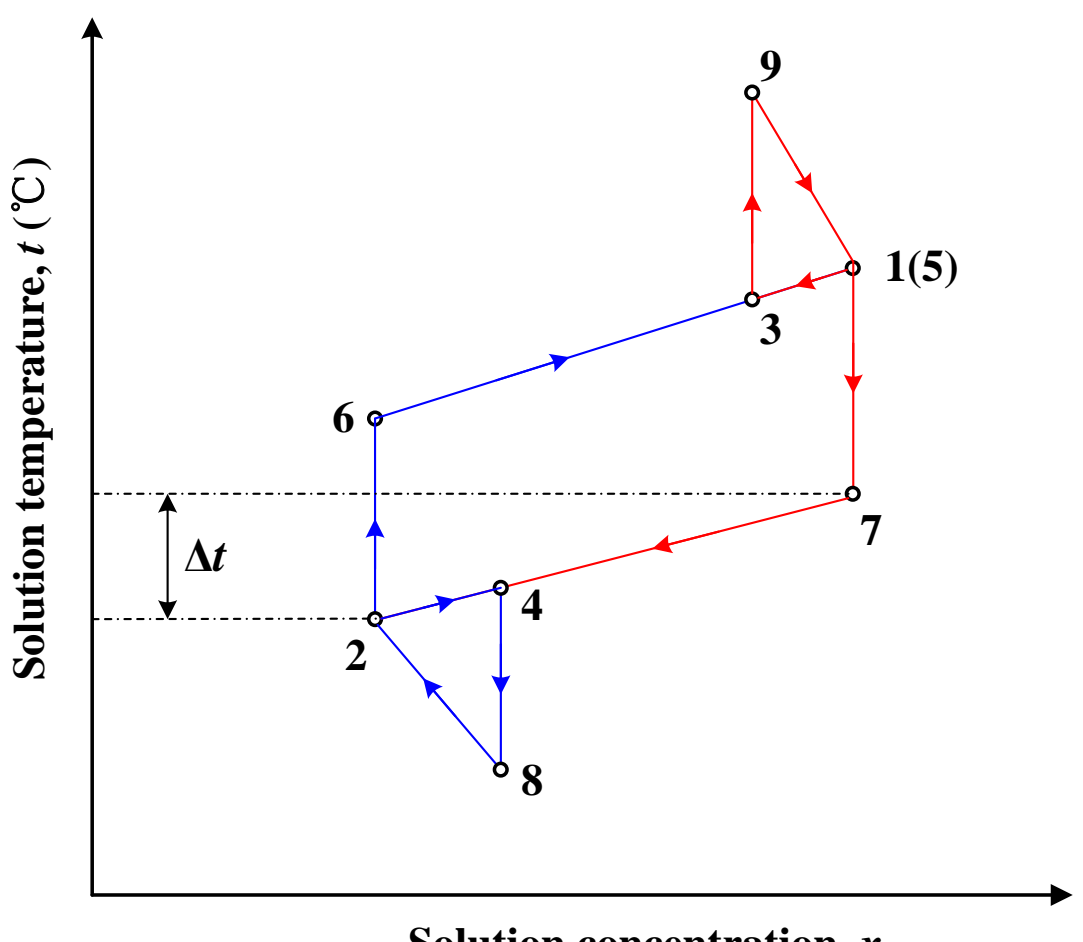

Solution concentration, $x$

Fig.2. $T-x$ diagram of solution in the conventional LDCH air-conditioning system 


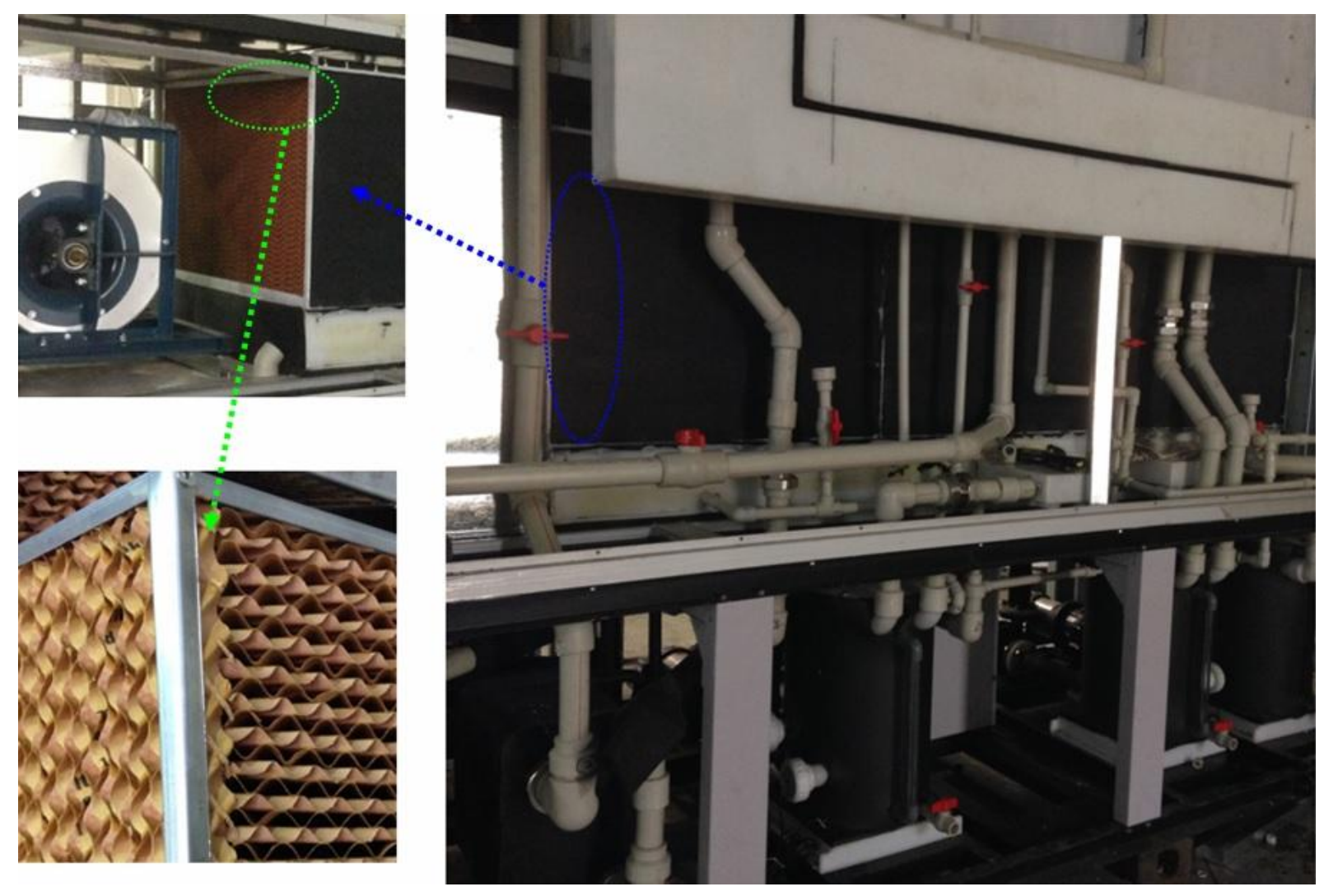

Fig.3. Photo of the LDCH air-conditioning experiment setup

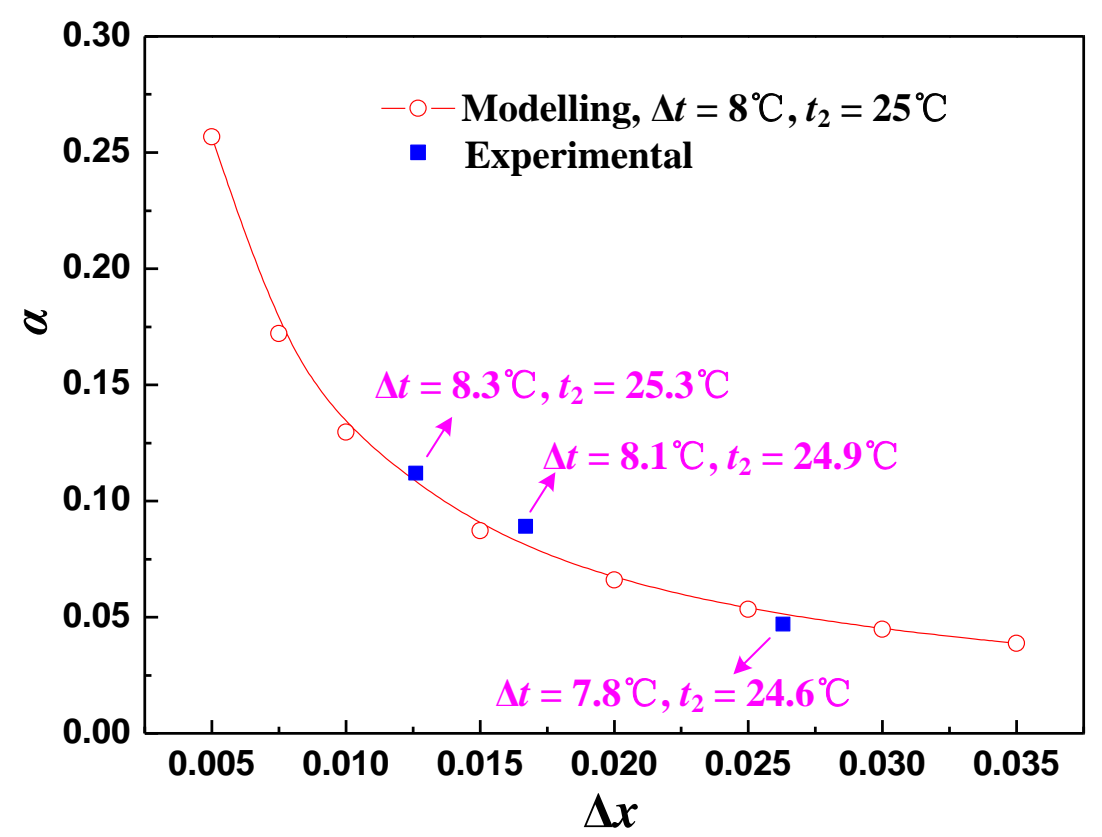

Fig.4. Branch fluid percentage of solution with solution concentration difference 


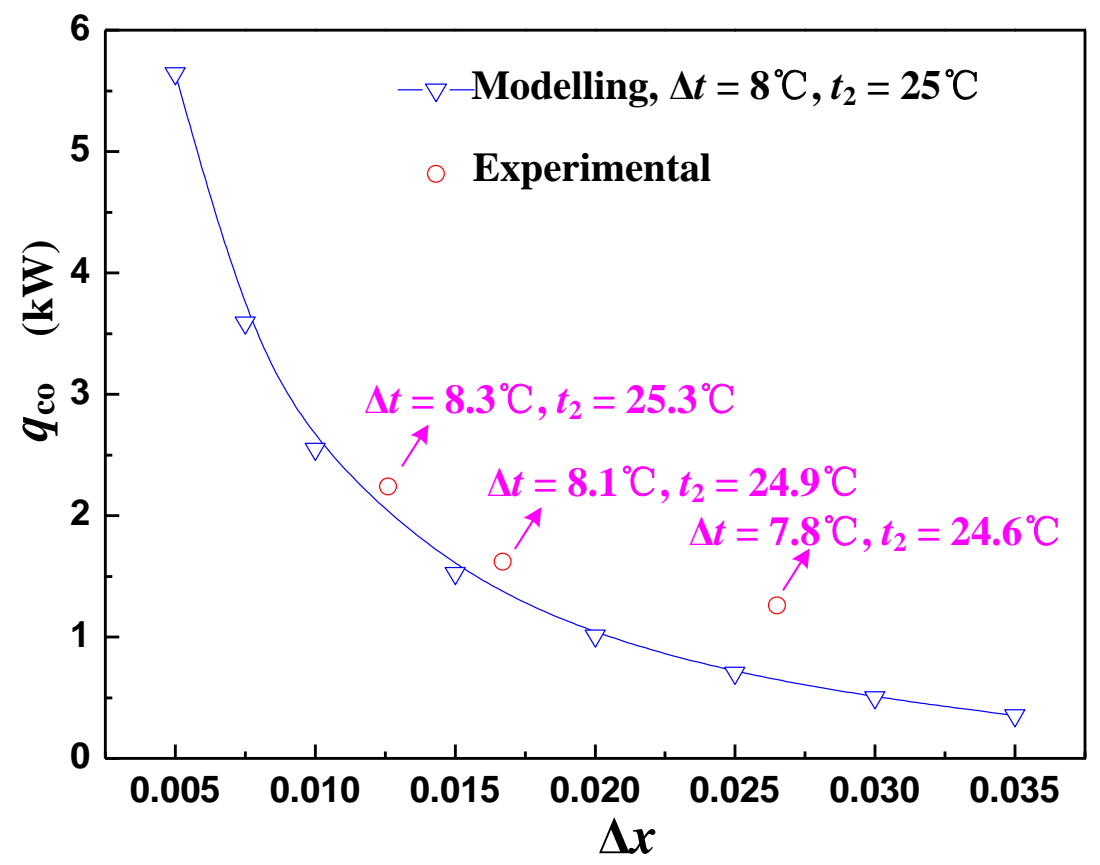

Fig.5. Cooling load loss with concentration difference of solution

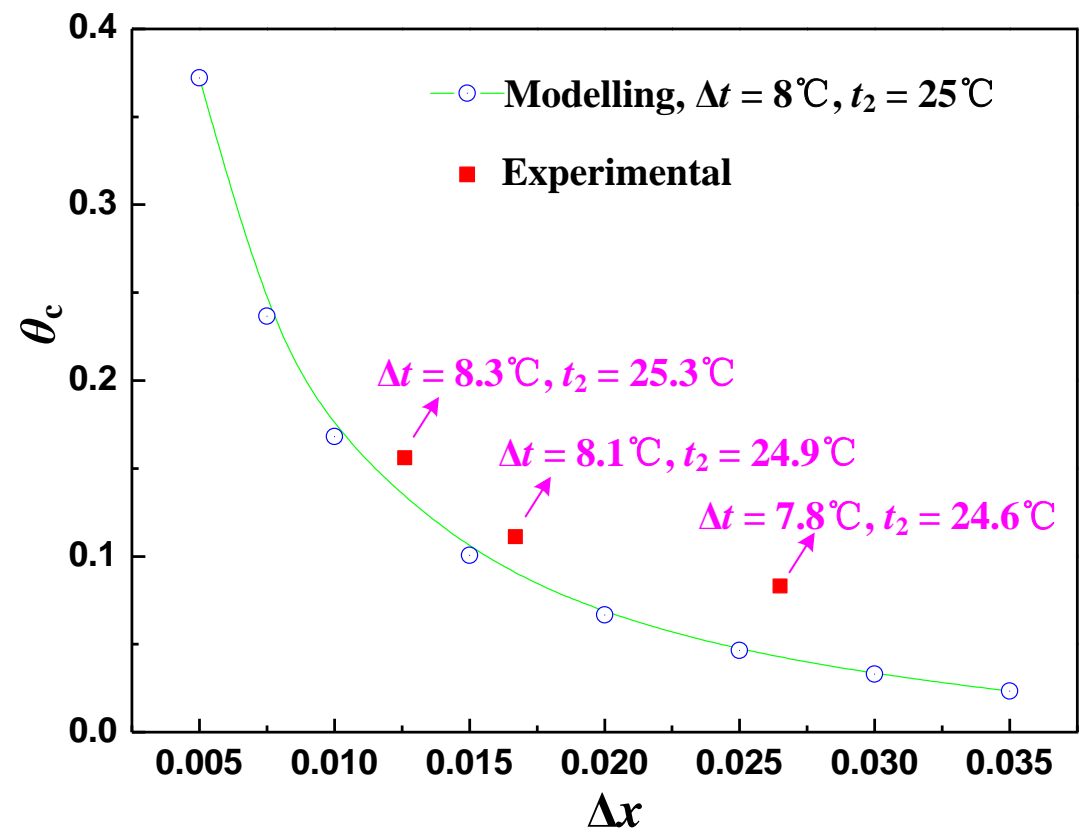

Fig.6. Loss percentage of cooling load with solution concentration difference 


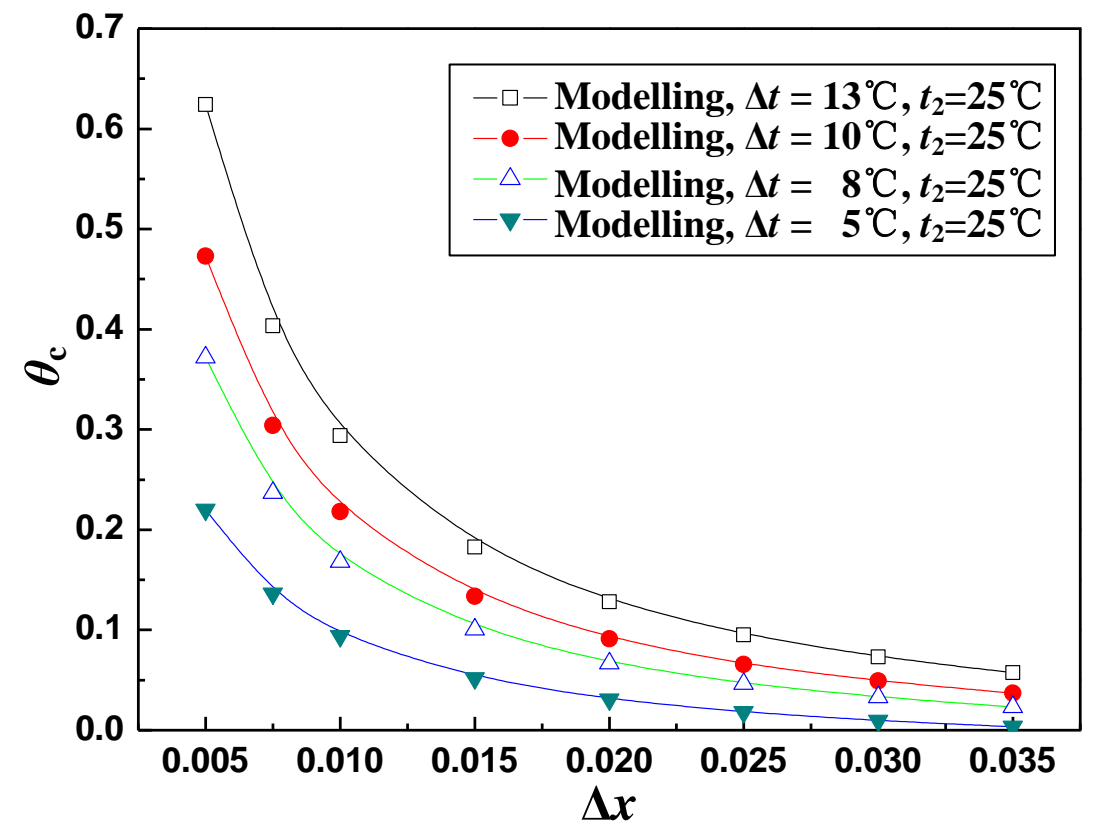

Fig.7. Loss percentage of cooling load of the evaporator with $\Delta x$ and $\Delta t$

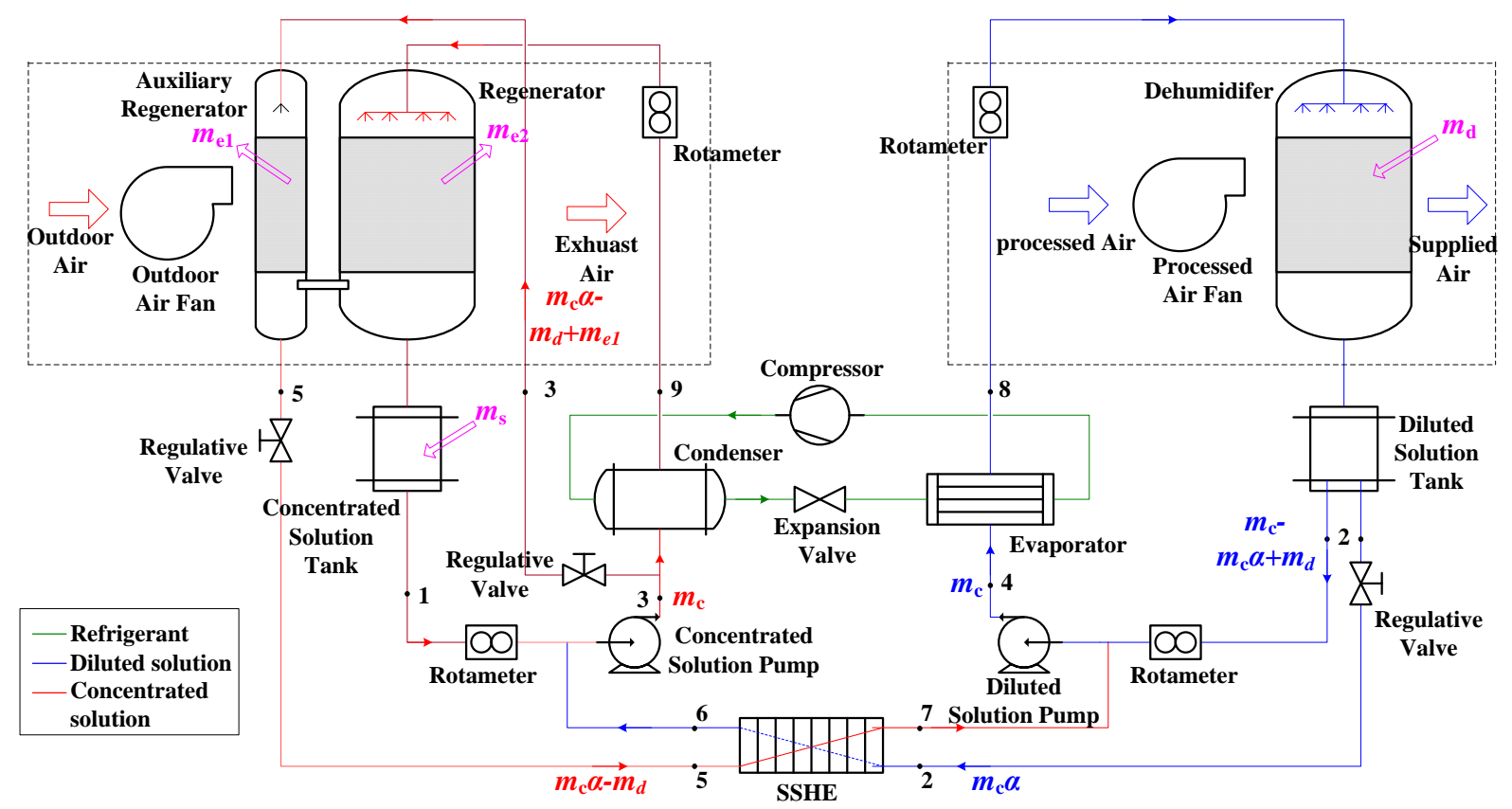

Fig.8. Schematic diagram of a new LDCH air-conditioning system 


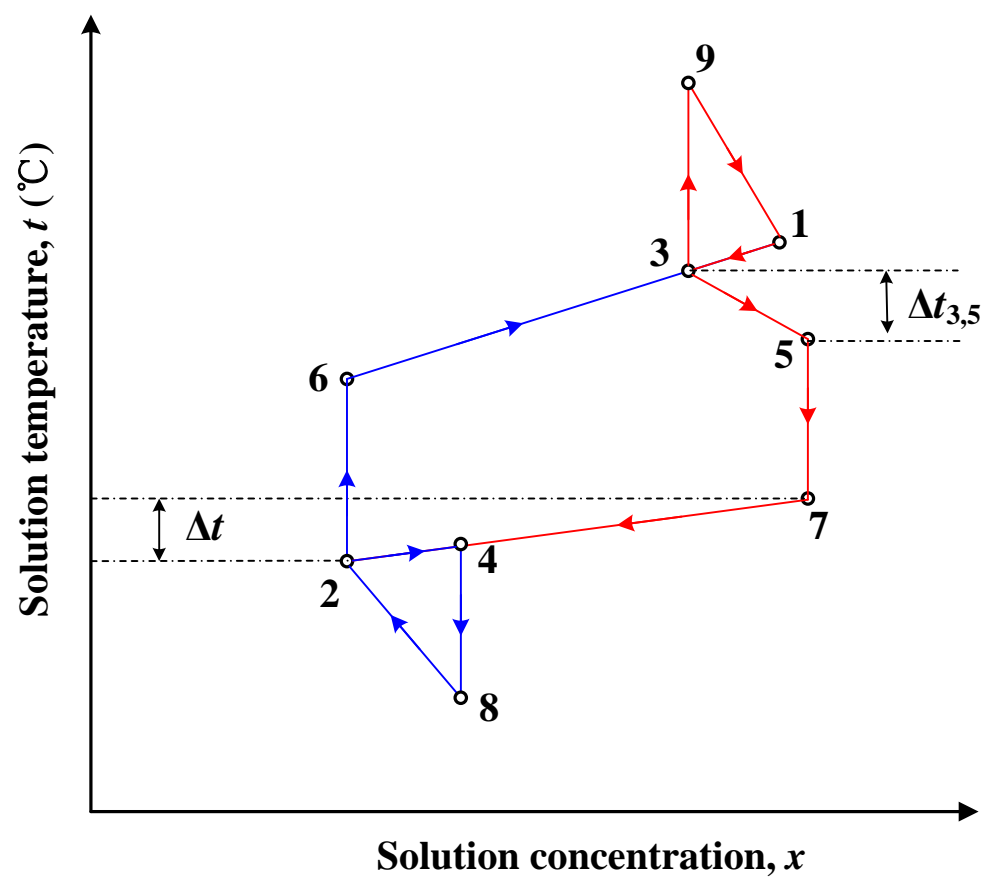

Fig.9. $T$ - $x$ diagram of solution in the new LDCH air-conditioning system

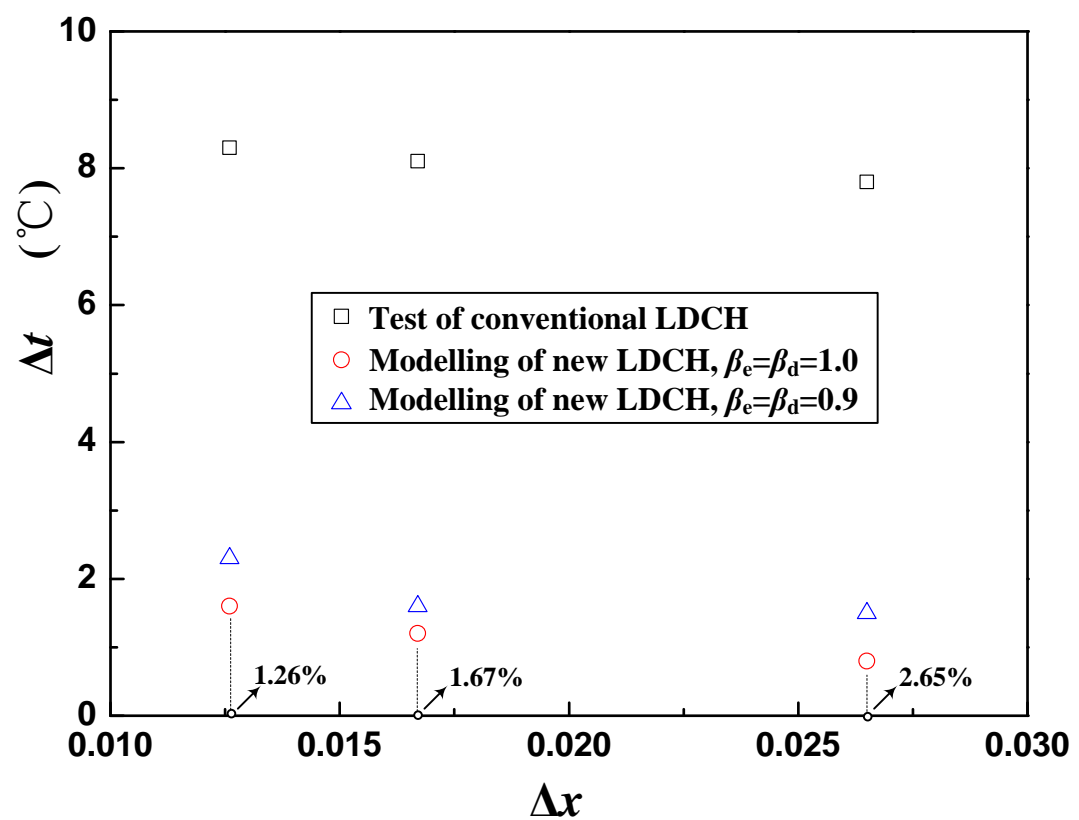

Fig.10. Variation of the solution temperature difference with concentration difference 


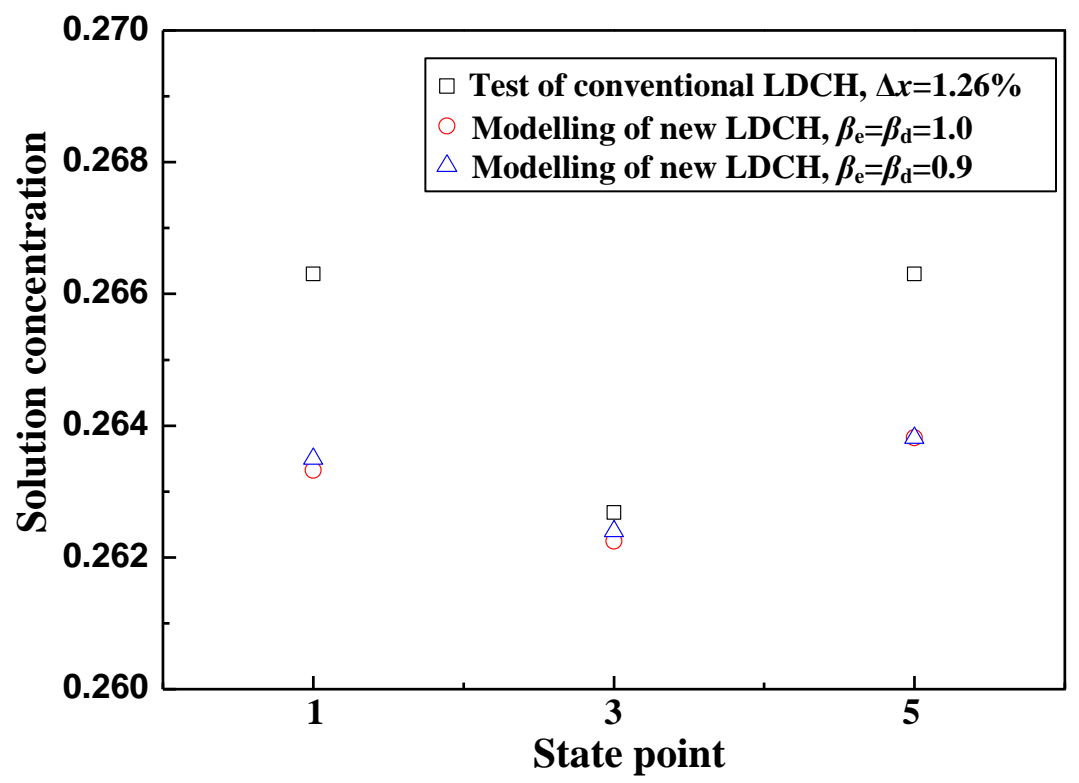

Fig.11. Comparison of solution concentration $(\Delta x=1.26 \%)$

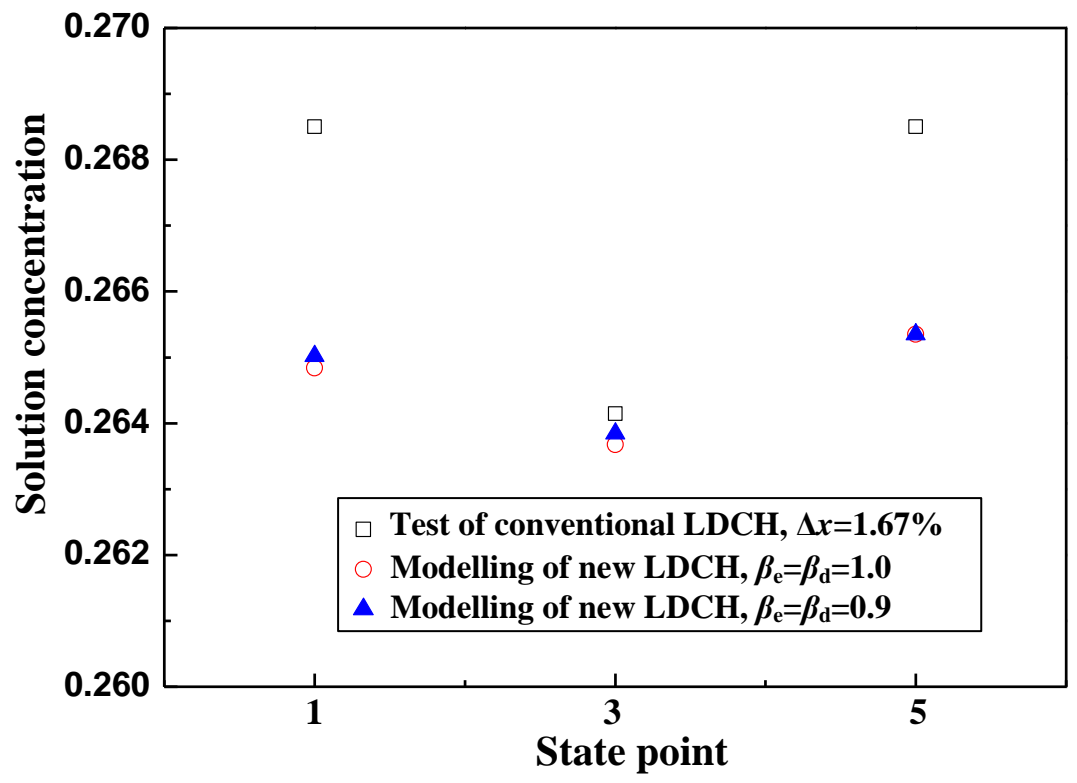

Fig.12. Comparison of solution concentration $(\Delta x=1.67 \%)$ 


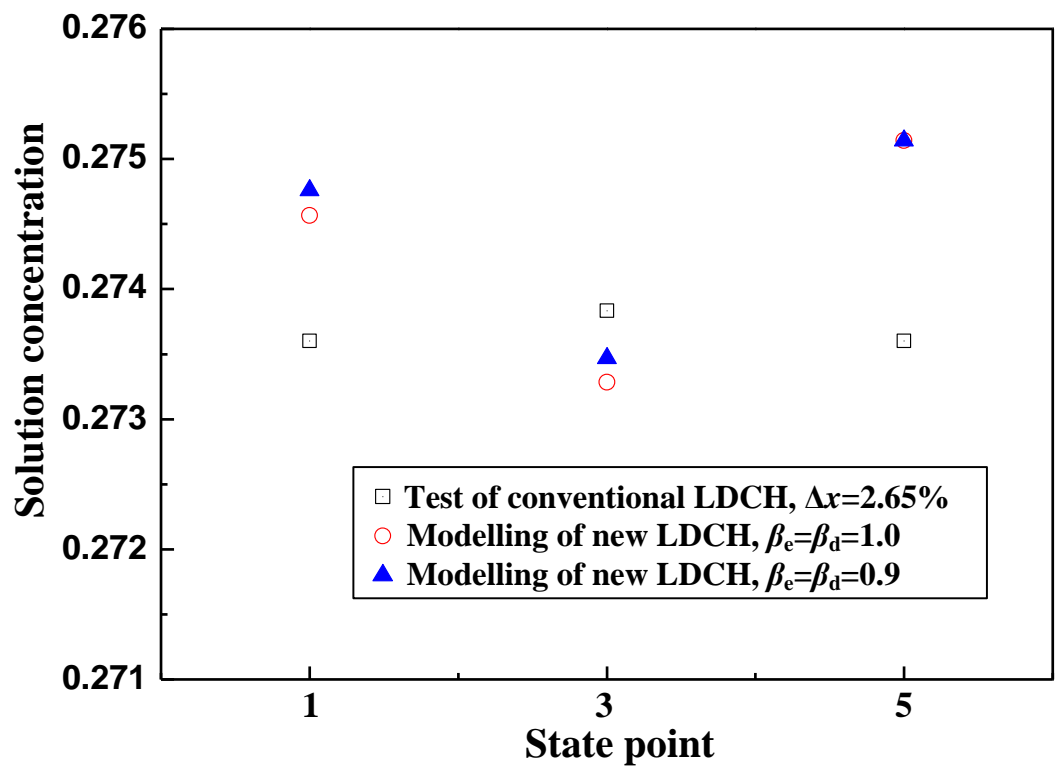

Fig.13. Comparison of solution concentration $(\Delta x=2.65 \%)$ 


\section{Table 1}

Specification of the different measuring devices

\begin{tabular}{llll}
\hline Parameters & Devices & Accuracy & Operational range \\
\hline Air dry-bulb temperature & K-type thermocouple & $\pm 0.1{ }^{\circ} \mathrm{C}$ & $0-100{ }^{\circ} \mathrm{C}$ \\
Humidity and temperature sensor & Rotronic HF534 & $\pm 0.8 \% \mathrm{RH} / \pm 0.1{ }^{\circ} \mathrm{C}$ & $0-99 \% /-40-85^{\circ} \mathrm{C}$ \\
Air flow rate & Spray nozzle & $\pm 3 \%$ & $500-4500 \mathrm{~m}^{3} / \mathrm{h}$ \\
Desiccant solution temperature & K-type thermocouple & $\pm 0.1{ }^{\circ} \mathrm{C}$ & $0-100{ }^{\circ} \mathrm{C}$ \\
Desiccant solution flow rate & ABGLW-25 & $\pm 1 \% \mathrm{R}$ & $0.5-10 \mathrm{~m}^{3} / \mathrm{h}$ \\
Desiccant solution density & Specific gravity hydrometer & $\pm 1 \mathrm{~kg} / \mathrm{m}^{3}$ & $1100-1900 \mathrm{~kg} / \mathrm{m}^{3}$ \\
Input power of the compressor & Digital power meter (WT230) & $\pm(0.1 \% \mathrm{R}+0.1 \% \mathrm{FS})$ & $15-600 \mathrm{~V} / 0.5-50 \mathrm{~A}$ \\
\hline
\end{tabular}

Table 2

Specification of the experimental results of LDCH system

\begin{tabular}{|c|c|c|c|}
\hline Parameters & $\Delta x=2.65 \%$ & $\Delta x=1.67 \%$ & $\Delta x=1.26 \%$ \\
\hline Input power of the compressor, $\mathrm{kW}$ & 8.47 & 8.32 & 8.29 \\
\hline Cooling capacity of the evaporator, $q_{\mathrm{eva}}, \mathrm{kW}$ & 14.81 & 14.59 & 14.36 \\
\hline Heating load of the condenser, $q_{\text {cond }}, \mathrm{kW}$ & 22.90 & 22.73 & 22.39 \\
\hline Outdoor air flow rate in the regenerator, $\mathrm{m}^{3 /} \mathrm{h}$ & 1701.2 & 1705.7 & 1712.5 \\
\hline Inlet dry/wet-bulb temperature of outdoor air in regenerator, ${ }^{\circ} \mathrm{C}$ & $34.9 / 28.0$ & $35.0 / 28.0$ & $34.9 / 28.1$ \\
\hline Outlet dry/wet-bulb temperature of outdoor air in regenerator, ${ }^{\circ} \mathrm{C}$ & $45.5 / 35.2$ & $45.2 / 35.1$ & $45.2 / 34.9$ \\
\hline Removal moisture by outdoor air in the regeneration, $m_{\mathrm{e}}, \mathrm{kg} / \mathrm{h}$ & 21.43 & 21.20 & 20.26 \\
\hline Removal heat load by outdoor air in the regenerator, $q_{\mathrm{e}}, \mathrm{kW}$ & 21.30 & 20.96 & 20.33 \\
\hline Circulating flow rate of solution pump, $m_{\mathrm{c}}, \mathrm{kg} / \mathrm{h}$ & 3506.4 & 3520.8 & 3517.2 \\
\hline Solution temperature in the concentrated solution tank, ${ }^{\circ} \mathrm{C}$ & 50.6 & 50.9 & 51.3 \\
\hline Processed air flow rate in the dehumidifier, $\mathrm{m}^{3 /} \mathrm{h}$ & 2852.5 & 2909.7 & 2912.5 \\
\hline Inlet dry/wet-bulb temperature of processed air in dehumidifier, ${ }^{\circ} \mathrm{C}$ & $34.9 / 28.0$ & $35.0 / 28.0$ & $34.9 / 28.0$ \\
\hline Outlet dry/wet-bulb temperature of processed air in dehumidifier, ${ }^{\circ} \mathrm{C}$ & $33.3 / 24.6$ & $33.5 / 24.8$ & $33.6 / 25.1$ \\
\hline Solution temperature in the diluted solution tank, ${ }^{\circ} \mathrm{C}$ & 24.6 & 24.9 & 25.3 \\
\hline Temperature difference of point 7 and $2, \Delta t=t_{7}-t_{2},{ }^{\circ} \mathrm{C}$ & 7.8 & 8.1 & 8.3 \\
\hline Absorbed moisture from processed air in dehumidifier, $m_{\mathrm{d}}, \mathrm{kg} / \mathrm{h}$ & 16.68 & 16.00 & 15.10 \\
\hline Removal cooling capacity by processed air in the dehumidifier, $\mathrm{kW}$ & 13.59 & 12.97 & 12.12 \\
\hline Cooling capacity loss, $q_{\mathrm{co}}, \mathrm{kW}$ & 1.22 & 1.62 & 2.24 \\
\hline Cooling capacity loss percentage, $\theta_{\mathrm{c}}$ & $8.2 \%$ & $11.1 \%$ & $15.6 \%$ \\
\hline Supplemented filling water in the regeneration side, $m_{\mathrm{s}}, \mathrm{kg} / \mathrm{h}$ & 4.76 & 5.20 & 5.16 \\
\hline Percentage of branch flow to circulating flow rate, $\alpha$ & 0.047 & 0.089 & 0.112 \\
\hline Concentration of Concentrated solution tank, $x_{1}, \%$ & 27.36 & 26.85 & 26.63 \\
\hline Concentration of diluted solution tank, $x_{2}, \%$ & 24.73 & 25.18 & 25.37 \\
\hline Concentration of solution point $3, x_{3}, \%$ & 27.38 & 26.41 & 26.27 \\
\hline Concentration of solution point $4, x_{4}, \%$ & 24.85 & 25.29 & 25.48 \\
\hline
\end{tabular}




\section{Table 3}

Comparison of the experiment and modelling

\begin{tabular}{|c|c|c|c|c|c|c|c|c|c|}
\hline \multirow{3}{*}{ Parameters } & \multicolumn{3}{|c|}{ Experiment of conventional LDHP system } & \multicolumn{6}{|c|}{ Modeling of the new LDHP system } \\
\hline & \multirow{2}{*}{$\Delta x=1.26 \%$} & \multirow{2}{*}{$\Delta x=1.67 \%$} & \multirow{2}{*}{$\Delta x=2.65 \%$} & \multicolumn{2}{|c|}{$\Delta x=1.26 \%$} & \multicolumn{2}{|c|}{$\Delta x=1.67 \%$} & \multicolumn{2}{|c|}{$\Delta x=2.65 \%$} \\
\hline & & & & $\beta_{\mathrm{d}}=\beta_{\mathrm{e}}=1.0$ & $\beta_{\mathrm{d}}=\beta_{\mathrm{e}}=0.9$ & $\beta_{\mathrm{d}}=\beta_{\mathrm{e}}=1.0$ & $\beta_{\mathrm{d}}=\beta_{\mathrm{e}}=0.9$ & $\beta_{\mathrm{d}}=\beta_{\mathrm{e}}=1.0$ & $\beta_{\mathrm{d}}=\beta_{\mathrm{e}}=0.9$ \\
\hline Air flow rate in the regenerator, $\mathrm{m}^{3 / \mathrm{h}}$ & 1712.5 & 1705.7 & 1701.2 & 1712.5 & 1712.5 & 1705.7 & 1705.7 & 1701.2 & 1701.2 \\
\hline Inlet dry/wet-bulb temperature of air in regenerator, ${ }^{\circ} \mathrm{C}$ & $34.9 / 28.1$ & $35.1 / 27.8$ & $34.9 / 28.0$ & $34.9 / 28.1$ & $34.9 / 28.1$ & $35.0 / 28.0$ & $35.0 / 28.0$ & $34.9 / 28.0$ & $34.9 / 28.0$ \\
\hline Outlet dry/wet-bulb temperature in regeneration side, ${ }^{\circ} \mathrm{C}$ & $45.2 / 34.9$ & $45.2 / 35.1$ & $45.5 / 35.2$ & $45.2 / 34.9$ & $45.2 / 34.9$ & $45.2 / 35.1$ & $45.2 / 35.1$ & $45.5 / 35.2$ & $45.5 / 35.2$ \\
\hline Circulating flow rate of solution pump, $m_{\mathrm{c}}, \mathrm{kg} / \mathrm{h}$ & 3517.2 & 3520.8 & 3506.4 & 3517.2 & 3517.2 & 3520.8 & 3520.8 & 3506.4 & 3506.4 \\
\hline Percentage of branch flow to circulating flow rate, $\alpha$ & 0.112 & 0.089 & 0.047 & 0.112 & 0.112 & 0.089 & 0.089 & 0.047 & 0.047 \\
\hline Temperature of concentrated solution tank, ${ }^{\circ} \mathrm{C}$ & 51.3 & 50.9 & 50.6 & 51.3 & 51.3 & 50.9 & 50.9 & 50.6 & 50.6 \\
\hline Outlet dry/wet-bulb temperature in auxiliary regenerator, ${ }^{\circ} \mathrm{C}$ & l & I & l & $36.1 / 28.9$ & $35.9 / 28.8$ & $35.9 / 28.7$ & $35.8 / 28.6$ & $35.4 / 28.4$ & $35.4 / 28.3$ \\
\hline Removal moisture by air in the auxiliary regeneration, $\mathrm{kg} / \mathrm{h}$ & I & l & l & 2.27 & 2.04 & 1.89 & 1.70 & 1.01 & 0.91 \\
\hline Removal heat load by air in the auxiliary regenerator, $\mathrm{kW}$ & l & I & l & 2.28 & 2.05 & 1.87 & 1.68 & 1.00 & 0.90 \\
\hline Temperature drop, $\Delta t_{3,5}=t_{3}-t_{5},{ }^{\circ} \mathrm{C}$ & l & I & l & 6.7 & 6.0 & 6.9 & 6.2 & 7.0 & 6.3 \\
\hline Temperature difference of point 7 and $2, \Delta t=t_{7^{-}} t_{2},{ }^{\circ} \mathrm{C}$ & 8.3 & 8.1 & 7.8 & 1.6 & 2.3 & 1.2 & 1.9 & 0.8 & 1.5 \\
\hline
\end{tabular}

